\title{
An Adjustment Restriction on Fish Quota: Resource Rents, Overcapacity and Recovery of Fish Stock
}

\author{
Diana van Dijk $^{1,4} \cdot$ Eligius M. T. Hendrix ${ }^{2} \cdot$ Rene Haijema $^{3} \cdot$ \\ Rolf A. Groeneveld ${ }^{4}$. Ekko C. van Ierland ${ }^{4}$
}

Accepted: 18 December 2015 / Published online: 4 January 2016

(C) The Author(s) 2016. This article is published with open access at Springerlink.com

\begin{abstract}
Management objectives of the European Union for North Sea fish stocks are shifting towards considering both biological sustainability and economic benefits. As part of multiannual management plans, an adjustment restriction on fish quota has been introduced. Its objective is to obtain an efficient fish stock and to reduce overcapacity for the fishing industry. We develop and apply a bi-level stochastic dynamic programming model to study the effect of a quota adjustment restriction on the net present value of resource rents, overcapacity and fish stock, when the system is recovering from a downward environmental shock. At level one, a policy maker sets the quota, considering fishermen behavior, stochastic fish stock dynamics, capital stock dynamics and a quota adjustment restriction. At level two, fishermen harvest myopically and make long-term investment decisions, assuming that fish stock and quota do not change over time. The two levels are linked by the quota, which is
\end{abstract}

$凶 \quad$ Diana van Dijk

Diana.vandijk@eawag.ch

Eligius M. T. Hendrix

Eligius.hendrix@wur.nl

Rene Haijema

Rene.haijema@wur.nl

Rolf A. Groeneveld

Rolf.groeneveld@wur.nl

Ekko C. van Ierland

Ekko.vanierland@wur.nl

1 Environmental Social Sciences, Swiss Federal Institute of Aquatic Science and Technology, Überlandstrasse 133, P.O. Box 611, Dübendorf 8600, Switzerland

2 Computer Architecture, Universidad de Málaga, E.T.S.I. Informática, Campus de Teatinos, 29071 Málaga, Spain

3 Logistics, Decision and Information Sciences, Wageningen University, Hollandseweg 1, 6706 KN Wageningen, The Netherlands

4 Environmental Economics and Natural Resources Group, Wageningen University, Hollandseweg 1, $6706 \mathrm{KN}$ Wageningen, The Netherlands 
optimized by the policy maker at level one and becomes a restriction for myopic harvest and long-term investment decisions of fishermen at level two. Our analysis suggests that in the long run, overcapacity can be reduced by $54 \%$ at modest costs, namely at a $1 \%$ reduction in the net present value of resource rents. Long and short run sustainability of the fish stock is not affected.

Keywords Fisheries management - Quota adjustment restriction - Investment behavior · Stochastic dynamic programming

\section{Introduction}

An important threat to the survival of many fish species and fisheries is the increase in fishing fleet capacity, caused by economic incentives of fishermen under open-access and poor management (Gordon 1954). As there is too much fleet capacity, it is necessary to reduce this in order to recuperate profits of fishermen and to prevent fish stocks from being overexploited (Pauly et al. 2002; Clark 2006). The success of a management system is specified in terms of biological, economic, social and political objectives of the fishing industry and the management authority. Balancing these objectives makes the implementation of policies one of the main challenges in fisheries management (Arnason 2009). Yet, many management systems have failed to prevent overfishing and have often resulted in an increase in investments in the fleet capacity, causing overcapacity. Another challenge for policy makers when adjusting quota on an annual basis is that it is highly dependent on uncertainty about current fish stock levels, their dynamics and environmental variability (Carson et al. 2009). Fluctuation in fish stocks leads to annual quota volatility (Daníelsson 2005), which in turn affects fishermen in their ability to make long-term investment plans (Kell et al. 2005).

In the European Union (EU), during the 1992 review of the common fisheries policy (CFP) it became obvious that there had been overinvestment and overexploitation (Guyader 2002), with the consequence of decreasing catches. A major reform of the CFP took place in 2002 and consisted of a new commitment to develop recovery and multiannual management plans for fish stocks. Despite the new measures, the CFP failed to tackle problems of overcapacity and overexploitation, and profits continued to drop. In 2011, two fishermen organizations demanded that economic, social and environmental sustainability be combined in the 2012 reform of the CFP (Europêche 2011). Since then, objectives of policy makers have been shifted towards considering economic benefits and biological sustainability. Eventually, in the 2013 reform of the CFP, multiannual management plans have been proposed to reduce annual quota volatility. The objective of these plans is to obtain both efficient fish stocks in the long run and to provide greater stability for the fishing industry by enabling operators to plan ahead. Stability is to be provided by restricting the annual change in quota, but besides setting quota, multiannual management plans also provide measures such as closed areas, mesh size, gear, inspections, monitoring and effort management.

One of the measures under multiannual management plans is a quota adjustment restriction. This measure restricts annual quota volatility in the sense that quota can at most be adjusted upward or downward by $15 \%$ with respect to the previous quota. There are, however, potential challenges with this quota adjustment restriction. First, if quota adjustment is restricted, the quota may not be reduced sufficiently in years of low recruitment and this can delay fish stock recovery (Kell et al. 2005). The quota also cannot increase by more than $15 \%$, which prevents benefiting from years of increased recruitment levels (Butter- 
worth 2007). Second, Bennear and Stavins (2007) have shown that a restriction on the policy instrument causes the policy maker to make sub-optimal decisions and that this has a negative impact on the net present value of resource rents. Dijk et al. (2013) show that when the quota are free of any restriction, and the policy maker accounts for dynamics in fish stock and capital stock, sustainability of the fish stock is realized, however at the cost of maintaining some overcapacity. This overcapacity is the result of fishermen not being able to adjust their capital stock to changes in the quota. While it is optimal according to the policy maker to maintain overcapacity, it can lead to a dissatisfied fishing industry, because maintaining overcapacity is costly. Consequently, it can turn up the pressure to reduce fluctuation in quota. The current objective of the policy maker therefore is to obtain both a long-term fish stock that maximizes expected fishing rents and to reduce overcapacity. However, a quota adjustment restriction may limit the resource rents from fishing, or delay fish stock recovery. Nevertheless, the policy maker may consider this a small price to pay for the political ambition to meet fishers' demand to have a more stable quota policy.

Studies on the quota adjustment restriction have made an attempt at understanding the effect of this rule on sustainability of fish stocks (Kell et al. 2005, 2006). They show that in the short run, the effect of the restriction depends on the starting condition of the fish stock, while in the medium and long run, the restriction hardly affects harvest and sustainability of the fish stock. The more restrictive the quota adjustment restriction, the stronger its impact. A quota adjustment restriction between 20 and $40 \%$ hardly affects harvest and sustainability of fish stock, while a $10 \%$ quota adjustment restriction leads to large changes in the stock size and affects the ability to achieve management targets.

These studies have a number of limitations. First, they perform simulations of historical data of quota and fish stock, while accounting for the quota adjustment restriction. This means that the simulated quota may be sub-optimal. Second, capital stock and revenues and costs from harvesting are not considered. It is therefore unknown what the economic impact is of the adjustment restriction on quota. Third, (Kell et al. 2005, 2006) focus on t path towards a long-term average, while it remains unknown what the effect is on the system when the fish stock deviates from this path, e.g. after a shock. Analysis of long-term values in a system with a quota adjustment restriction does not provide sufficient insight in the effect of such a restriction on recovery of fish stocks and on overcapacity. The effect of a quota adjustment restriction is better measured for system states that deviate from long-term stability. Finally, although the objective of the quota adjustment restriction is to address both recovery of fish stocks and overcapacity, fishermen behavior in terms of planning and adjusting fleet capacity is not incorporated in the studies of Kell et al. (2005, 2006). This is a limitation, because the policy maker makes assumptions about harvest and investment behavior when setting the quota.

There exists extensive theoretical literature on investment behavior of fishermen, but because of limited data availability there are few empirical studies that analyze investment in fisheries (Tsitsika and Maravelias 2008). To the best of our knowledge, there is no general agreement or evidence from data that fishermen operate with a short-time view, i.e. they act myopically, or that they have a long planning horizon when they make harvest and investment decisions. Harvest behavior has been modeled with an infinite planning horizon (Clark et al. 2005; Daníelsson 2005; Singh et al. 2006; Kulmala et al. 2008), as well as myopically (Hämäläinen et al. 1990; Sandal and Steinshamn 2004; Olaussen and Skonhoft 2008; Dijk et al. 2013). It has been suggested that myopic harvest is not far off from true fishermen behavior (Karagiannakos 1996; Grafton et al. 2006; European Commission 2009).

The objective of this paper is to study the effect of a quota adjustment restriction on the net present value of resource rents, overcapacity and recovery of fish stock, while considering 
biological and economic variables. We first look at the long-term effect of different levels of quota adjustment restriction and then introduce a downward environmental shock on the fish stock. To compare with Kell et al. (2005, 2006), we study the effect of different levels of quota adjustment restriction, including 30,15, 10 and 5\% restrictions. The analysis is based on a bi-level stochastic dynamic programming (SDP) model. A deterministic bi-level framework is developed in Homans and Wilen (1997) to study the combined implementation of a quota and season length, which are each determined at a different level. This model is extended in Anderson (2000) to account for disaggregated vessel level behavior and to allow for political intervention. A stochastic extension of the model is presented in Rocha and Gutiérrez (2012), by assuming unknown current levels of fish stock. Characteristic to the bi-level model in our study is that decisions of the policy maker and fishermen are made sequentially at their first and second levels, respectively. In game theory such a setting is called a leader-follower or Stackelberg stage game, where the optimal policy of the leader (the policy maker) is determined by the reaction of the follower (fishermen) (Munro et al. 2012). Most game theoretic studies simplify the problem by using a single-stage approach where each player makes a decision at the beginning of the game, given observed states that change deterministically over time (Bailey et al. 2010). Fewer studies use a multi-stage approach, where players make a decision at stage one that is independent of the other player's behavior. At stage two, each player uses decisions from stage one to decide on the best strategy (Ruseski 1998; Quinn and Ruseski 2001; Kronbak and Lindroos 2006).

In our bi-level model, at level one, the policy maker determines each year the quota according to the decision rule that maximizes the net present value of resource rents, while anticipating fishermen behavior, stochastic fish stock dynamics, capital stock dynamics and a quota adjustment restriction. This quota adjustment restriction is incorporated by means of a restriction on the change in the quota, which states that the quota cannot deviate, upward or downward, by more than $30,15,10$ or $5 \%$ from the quota in the previous year. At level two, fishermen make myopic harvest decisions and long-term investment decisions, for which it is assumed that fish stock and quota do not change over time. This can be considered as a rather simple expression of fishermen behavior. We do not assume adaptive or rational expectations (or other advanced mechanisms) for the behavior of fishermen. The two levels are linked by the optimal quota, which is set at level one and becomes a restriction at level two. The model differs from Ruseski (1998) and Kronbak and Lindroos (2006) by means of its dynamic perspective, which is that the policy maker adjusts the quota on an annual basis, based on the decision rule that maximizes the net present value of resource rents, while anticipating fishermen behavior, stochastic fish stock dynamics, capital stock dynamics and a quota adjustment restriction. See Bailey et al. (2010) for an overview of the application of game theory to fisheries over the last 30 years.

The contribution of this paper is as follows. Where Kell et al. (2005, 2006) determine quota through simulations of historical data, we optimize the quota with an adjustment restriction. Compared to the static multi-stage games in Ruseski (1998) and Kronbak and Lindroos (2006), we incorporate dynamics by optimizing the quota annually. This optimal quota is consequently used in a simulation to study the effect of the adjustment restriction on the net present value of resource rents, overcapacity and recovery of fish stock. Although Homans and Wilen (1997), Anderson (2000) and Rocha and Gutiérrez (2012) study fisheries policies with a similar bi-level framework, they do not focus on the problem of overcapacity. Furthermore, in order to study fish stock recovery and overcapacity, dynamics in both fish stock and capital stock are considered when determining the optimal quota. Finally, resource rents are compared for the case of a quota without adjustment restriction and a quota with adjustment restriction. 


\section{The Model}

We present a bi-level stochastic dynamic programming (SDP) model, where at level one the policy maker determines the quota that maximizes resource rents, while anticipating fishermen behavior, stochastic fish stock dynamics, capital stock dynamics and a quota adjustment restriction. At level two, fishermen decide on their short-term harvest and long-term investment levels. For long-term investment fishermen assume that the fish stock and quota will remain at the current levels. Although decisions of the policy maker and fishermen are made sequentially, the two levels are linked by the quota that is derived at level one and becomes a restriction for fishermen at level two.

\subsection{Fishermen Decisions}

We first describe the decisions at level two, i.e. fishermen behavior with respect to harvest and investment. We assume that fishermen base their harvest decisions on current costs, fish prices, capital stock, pre-harvest fish stock and a quota restriction set by the policy maker. Because the harvesting costs, i.e. the effect on future fish stock, are shared with the entire fleet, individual fishermen are assumed to ignore the long-term consequences of their harvest decisions, making harvest a short-term decision. In contrast, investment in capital is considered a long-term decision, which fishermen make based on pre-harvest fish stock, capital stock and quota. Parameter values (see Table 1) are based on literature as explained in Dijk et al. (2013) and in the data section.

\subsubsection{Myopic Harvest Behavior}

In the literature on fisheries economics, harvest behavior has been modeled with different assumptions concerning the planning horizon. It is common to assume either an infinite planning horizon (Clark et al. 2005; Singh et al. 2006; Kulmala et al. 2008) or a short planning horizon (Hämäläinen et al. 1990; Sandal and Steinshamn 2004; Olaussen and Skonhoft 2008; Dijk et al. 2014). Nevertheless, myopic harvest has been considered to be close to true fishermen behavior (Karagiannakos 1996; Grafton et al. 2006; European Commission 2009). We specify harvest behavior based on current fish, capital and quota levels.

In this model, fishermen react on costs and revenues from harvesting, depending on the experienced level of fish stock $x_{t}$ and on restrictions due to capital stock $k_{t}$ and quota $Q_{t}$. This quota is determined by the policy maker. A Spence harvest function is used to represent the relation between harvest $h_{t}$, fish stock $x_{t}$ and effort $E_{t}$ (Spence 1973):

$$
h_{t}=x_{t}\left(1-e^{-q E_{t}}\right) \rightarrow E\left(x_{t}, h_{t}\right)=\frac{1}{q} \ln \left(\frac{x_{t}}{x_{t}-h_{t}}\right) .
$$

Harvest $h_{t}$ and fish stock $x_{t}$ are expressed in kton, while effort $E_{t}$ is expressed in million horse power days, mln hpd, and the catchability coefficient $q$ is expressed in mln $h p d^{-1}$. In Conrad and Clark (1987), $\frac{c}{p q}$ has been identified as the bioeconomic equilibrium escapement, where $c$ stands for the cost per unit of effort and $p$ is the unit price of fish. This is the stock size where the marginal benefits from fishing to an individual fisherman equal the marginal costs. This is usually called the open access fish stock. In this model we incorporate the cost per unit of effort $c_{E}$, which includes maintenance, haul-in, haul-out and storage. Crew costs are included separately as the cost per unit of revenue $c_{R}$, so that the open access fish stock $\hat{x}$ is

$$
\hat{x}=\frac{c_{E}}{p q\left(1-c_{R}\right)} .
$$


Table 1 Parameter and variable values from Dijk et al. (2013)

\begin{tabular}{|c|c|c|c|}
\hline Symbol & Definition & Value & Unit \\
\hline \multicolumn{4}{|c|}{ Biological parameters } \\
\hline$\hat{x}$ & Open access stock of North Sea plaice & 185.6 & kton \\
\hline$r$ & Intrinsic growth rate of North Sea plaice & 0.74 & $\%$ \\
\hline$M$ & Carrying capacity of North Sea plaice & 460 & kton \\
\hline$\alpha$ & Quota restriction & \pm 15 & $\%$ \\
\hline$\mu$ & Mean of the lognormally distributed $z_{t}$ & -0.0126 & \\
\hline$\sigma$ & Standard deviation of random variable $z_{t}$ & 0.16 & \\
\hline \multicolumn{4}{|c|}{ Economic parameters } \\
\hline$p$ & Price & $1.83 \times 10^{6}$ & $€ /$ kton \\
\hline$q$ & Catchability coefficient & 0.0139 & $\operatorname{mln~hpd} d^{-1}$ \\
\hline$c_{E}$ & Effort cost & $3.54 \times 10^{6}$ & $€ / \mathrm{mln}$ hpd \\
\hline$c_{R}$ & Crew cost & 0.25 & $\%$ \\
\hline$c_{i}$ & Investment cost & $2.1 \times 10^{6}$ & $€ / \mathrm{mln}$ hpd \\
\hline$\delta$ & Discount factor & 0.95 & \\
\hline$\gamma$ & Vessel depreciation rate & 10 & $\%$ \\
\hline \multicolumn{4}{|c|}{ Biological variables } \\
\hline$x_{t}$ & Stock size of North Sea plaice & $\in[\hat{x}, M]$ & kton \\
\hline$h_{t}$ & Harvest of North Sea plaice & $\in\left[0, Q_{t}\right]$ & kton \\
\hline$Q_{t}$ & Quota for North Sea plaice & $\in[0, M-\hat{x}]$ & kton \\
\hline$z_{t}$ & i.i.d. random variable & $\sim \log n(\mu, \sigma)$ & \\
\hline \multicolumn{4}{|c|}{ Economic variables } \\
\hline$k_{t}$ & Fleet capacity of North Sea plaice fishery & $\in\left[0, \frac{1}{q} \ln \frac{M}{\hat{x}}\right]$ & mln hpd \\
\hline$i_{t}$ & Investment in capital stock & $\in[0, \infty]$ & mln hpd \\
\hline$E_{t}$ & Fleet effort North Sea plaice & $\in[0, k]$ & mln hpd \\
\hline$\pi_{t}$ & Net present value of resource rents & & $\operatorname{mln} €$ \\
\hline \multicolumn{4}{|c|}{ Grid of the state space } \\
\hline$\frac{1}{q} \ln \frac{M}{\hat{x}}$ & Maximum fleet capacity & 74 & mln hpd \\
\hline$n_{x}$ & Number of equidistant levels for $x_{t}$ & 23 & \\
\hline$n_{k}$ & Number of equidistant levels for $k_{t}$ & 23 & \\
\hline$n_{Q}$ & Number of equidistant levels for $Q_{t-1}$ & 28 & \\
\hline
\end{tabular}

Under pure open access, harvest takes place for a fish stock $x_{t}>\hat{x}$. In that case, the open access harvest level is $\tilde{h}\left(x_{t}\right)=\left(x_{t}-\hat{x}\right)^{+}$, where the operator $(y)^{+}=\max \{0, y\}$. In restricted open access, fishermen are also confronted with quota $Q_{t}$, expressed in kton, so that the harvest is

$$
\hat{h}\left(x_{t}, Q_{t}\right)=\min \left\{\tilde{h}\left(x_{t}\right), Q_{t}\right\} .
$$

The effort is restricted by the fleet size $k_{t}$ expressed in the same units, $E_{t} \leq k_{t}$. This means that fishermen cannot harvest more than what their capital stock allows. The maximum possible harvest given the available capital stock is $h\left(x_{t}, k_{t}\right)=x_{t}\left(1-e^{-q k_{t}}\right)$. This gives the following myopic harvest rule: 


$$
h\left(x_{t}, k_{t}, Q_{t}\right)=\min \left\{\hat{h}\left(x_{t}, Q_{t}\right), x_{t}\left(1-e^{-q k_{t}}\right)\right\}
$$

\subsubsection{Long-Term Investment Behavior}

We now develop a long-term investment rule for fishermen. Although the length of the planning horizon is subject to considerable debate (Link et al. 2011), it is common to assume that fishermen decide over the long-term (Eisenack et al. 2006; Singh et al. 2006; Kulmala et al. 2008). In Eisenack et al. (2006) long-term investment decisions are determined for a multiple number of identical fishing firms, while in Singh et al. (2006) it concerns the investment decision of a sole owner. In both studies, decisions are based on known dynamics in fish stock and capital stock. It is thereby ignored that fisheries are often managed by a resource manager, where each party may have different knowledge about fish stock dynamics. In fact, it is unlikely that fishermen have the same knowledge about fish stock growth and future values of fish stock as a policy maker.

In this model we therefore assume that fishermen have no information about fish stock dynamics and that the observed fish stock is constant during the investment planning horizon. The policy maker, whose quota decision will be addressed in Sect. 2.2, does have information about fish stock growth and can therefore anticipate future dynamics. Similarly, it is assumed that fishermen have no knowledge about future quota. They therefore consider the current quota as the future one in their investment decision. That is, the long-term investment decision is based on observed levels of current fish stock $x_{t}$, capital stock $k_{t}$ and quota $Q_{t}$, where the latter is set by the policy maker. The objective of fishermen is to choose a future investment path $i_{t+j}, j=0, \ldots, \infty$ such that the sum of the discounted future profits is maximized:

$$
\max _{i_{t+j}}\left\{\sum_{j=0}^{\infty} \frac{\pi\left(x_{t}, k_{t+j}, Q_{t}, i_{t+j}\right)}{(1+\rho)^{j}}\right\}
$$

with

$$
\pi(x, k, Q, i)=\left(1-c_{R}\right) \operatorname{ph}(x, k, Q)-c_{E} E(x, k, Q)-c_{i} i
$$

where $\rho$ is the exogenous discount rate and where the fleet is foreseen to develop according to

$$
k_{t+j+1}=(1-\gamma) k_{t+j}+i_{t+j} .
$$

The discounted future profit in (5) are based on revenues from harvest $p h$ minus effort costs $c_{E} E$, crew costs $c_{R} p h$ and investment costs $c_{i} i$. As in Elliston and Cao (2006), we include crew costs as a constant share per unit of revenue. Decisions $h_{t+j}, E_{t+j}, i_{t+j}$ are determined by current observed fish stock $x_{t}$, capital stock $k_{t+j}$ and by the decision of the policy maker, quota $Q_{t}$. Decision $E_{t+j}$ follows from $h_{t+j}=h\left(x_{t}, k_{t+j}, Q_{t}\right)$. A constraint is included, namely fishermen assume for all years $t+j$ that both fish stock $x_{t}$ and quota $Q_{t}$ remain constant at levels $x_{t}$ and $Q_{t}$.

A good approximation of the optimum investment level $i_{t}$ of problem (5), (6), (7) can be derived from the following reasoning. Consider that fishermen invest such that the investment extends in one period directly to the capital level corresponding to long-run harvest $\bar{h}$, given fish stock $x$ and quota $Q$. Investment is zero if the capital stock exceeds this level:

$$
i(x, k, Q)=\left\{\frac{1}{q} \ln \left(\frac{x}{x-\bar{h}}\right)-(1-\gamma) k\right\}^{+}
$$


with

$$
\bar{h}=\min \left\{x-\frac{c_{E}+c_{i} \gamma}{p q\left(1-c_{R}\right)}, Q\right\} .
$$

For a derivation see "Appendix 1".

\subsection{The Policy Maker}

At level one, a policy maker sets the quota, considering fishermen behavior, stochastic fish stock dynamics, capital stock dynamics and a quota adjustment restriction. We first present the bio-economic model for optimal quota adjustment and then describe the solution method of stochastic dynamic programming in terms of all its components.

\subsubsection{Bio-economic Model for Annual Quota Adjustment}

At level one, the policy maker determines the annual quota for the fishing industry. ${ }^{1}$ The objective of the policy maker is to determine the quota $Q_{t}$ that maximizes the net present value of resource rents $\pi_{t}$,

$$
\max _{Q_{t}} \mathbb{E}\left\{\sum_{t=0}^{\infty} \frac{\pi\left(x_{t}, k_{t}, Q_{t}, i\left(x_{t}, k_{t}, Q_{t}\right)\right)}{(1+\rho)^{t}}\right\},
$$

with resource rents $\pi_{t}$ according to (6). We incorporate a quota adjustment restriction by means of a restriction on the change in the quota:

$$
A \leq Q_{t} \leq B,
$$

where $A=Q_{t-1}(1-\alpha)$ and $B=Q_{t-1}(1+\alpha)$, and where $Q_{t-1}(1-\alpha) \leq Q_{t} \leq Q_{t-1}(1+\alpha)$ states that the quota cannot deviate more than $\alpha$ from the previous quota $Q_{t-1}$.

Harvest $h_{t}$ in (4) and investment $i_{t}$ in (8) are fishermen decisions at level two, that are determined by fish stock $x_{t}$, capital stock $k_{t}$ and the quota decision $Q_{t}$ of the policy maker. This means that the policy maker anticipates harvest and investment decisions of fishermen, which coincide with the harvest and investment rules in (4) and (8). The difference is that the policy maker has information about future, stochastic fish stock development and uses this information to protect the fishery from overinvestment and overfishing. In the objective function of the policy maker the notation $\mathbb{E}$ therefore represents the expectation taken over possible outcomes of fish stock $x_{t}$ and capital stock $k_{t}$. Fish dynamics are modeled as

$$
x_{t+1}=x_{t}+z_{t} r x_{t}\left(1-\frac{x_{t}}{M}\right)-h_{t},
$$

where stochastic fish stock growth is represented by an i.i.d. random variable $z_{t}$ that is lognormally distributed. The fleet develops according to

$$
k_{t+1}=(1-\gamma) k_{t}+i_{t} .
$$

\subsubsection{Solution Method: Stochastic Dynamic Programming}

The model for setting the quota can be solved numerically using stochastic dynamic programming. We assume an infinite horizon problem with discrete time steps. In each year, the

1 In this model setting, it is assumed that fishermen perfectly comply with the enforced quota. Problems related to non-compliance are discussed in, among others (Nielsen 2003; Grafton et al. 2010; Fulton et al. 2011). 
quota can at most be adjusted upward or downward by a specified percentage with respect to the quota in the previous period. Following the literature on stochastic dynamic programming (Howard 1960; Puterman 1994; Judd 1998), we discuss the state (space), decision (space), state transition (probabilities), the contribution, the Bellman equation and computational complexity. In particular we pay attention to the implementation of the solution method.

State and State Space The state is the state of fish stock $x_{t}$ and capital stock $k_{t}$ at the start of year and the quota from the previous period $Q_{t-1}$, because each year the quota decision $Q_{t}$ can at most be adjusted upward or downward by a specified percentage with respect to $Q_{t-1}$; the state is $\left(x_{t}, k_{t}, Q_{t-1}\right)$. The state space is continuous, as fish stock $x_{t}$, capital $k_{t}$ and last year's quota $Q_{t-1}$ are continuous. For numerical calculations a grid is chosen with $n_{x}$ levels of $x, n_{k}$ levels of $k$, and $n_{Q}$ levels of quota. The grid consists of $n_{x} \times n_{k} \times n_{Q}$ states. To simplify notations, the state is denoted as $\left(x_{t}, k_{t}, Q_{t-1}\right)$ irrespective of the value of $t$.

Decision and Decision Space The decision is $Q_{t}$, the quota that holds for year $t$. The decision space is continuous and does not require a grid, for reasons explained below.

Transition and Transition Probabilities State transitions from $\left(x_{t}, k_{t}, Q_{t-1}\right)$ to $\left(x_{t+1}\right.$, $k_{t+1}, Q_{t}$ ) follow Eqs. (12) and (13). In (12), $z_{t}$ is a continuous stochastic variable, which has been discretized into 40 quantiles of the underlying probability distribution. For evaluating a decision in a particular state, we consider thus forty transitions with equal probability 0.025 . Although transitions will be considered from all states $\left(x_{t}, k_{t}, Q_{t-1}\right)$ on the grid, the resulting states $\left(x_{t+1}, k_{t+1}, Q_{t}\right)$ usually are not on the grid. In discussing the Bellman equation we explain how we deal with this issue.

Contribution The objective function (10) is separable in contributions per period in (6).

Bellman Equation The objective function can be defined recursively:

$$
V\left(x_{t}, k_{t}, Q_{t-1}\right)=\max _{A \leq Q_{t} \leq B}\left\{\pi\left(x_{t}, k_{t}, Q_{t}, i\left(x_{t}, k_{t}, Q_{t}\right)\right)+\delta \mathbb{E}\left[V\left(x_{t+1}, k_{t+1}, Q_{t}\right)\right]\right\} .
$$

$V_{t}$ is the value function that represents the maximized value of the objective function from time t onwards, $\delta=1 /(1+\rho)<1$ is the exogenous discount factor. Note that because both the discount rate $\rho$ and discount factor $\delta$ are exogenous, the number of variables does not change by using $\rho$ or $\delta . \mathbb{E}$ is the expectations operator that holds the transition probabilities of moving from a given current state of fish stock $x_{t}$ to next period's fish stock $x_{t+1}$. Restrictions on quota $Q_{t}$ are given by $A$ and $B$ in (11). Assuming a long horizon of $T$ years, we can solve the maximization problem recursively, starting with $V_{T}\left(x_{T}, k_{T}, Q_{T-1}\right)=0$, for all $n_{x} \times n_{k} \times n_{Q}$ states on the grid. Next, successively $V_{T-1}, V_{T-2}, \ldots, V_{2}, V_{1}$ are computed for all states on the grid. For states that are not on the grid, the state values are derived by interpolation.

Computational Complexity For the bounds of the state space of fish stock, we have $x_{t} \in$ $[\hat{x}, M]$. Because of the assumption that $h_{t}=0$ if $x_{t}<\hat{x}$, we do not consider values below $\hat{x}$. From this assumption follows that a reasonable range for optimal quota is $Q_{t} \in[0, M-\hat{x}]$. Finally, for the bounds of the state space of capital stock we have $k_{t} \in\left[0, \frac{1}{q} \ln \frac{X}{\hat{x}}\right]$. The grid of the state space has equidistant levels of $x_{t}, k_{t}$ and $Q_{t-1}$. For each state $\left(x_{t}, k_{t}, Q_{t-1}\right)$ a nonlinear search procedure is applied, in which interpolation is used to estimate state values.

The numerical procedure of (14) is also known as Value Function Iteration. For a general description of the value iteration process see Puterman (1994). A technical explanation of this specific bi-level SDP model is provided in Dijk et al. (2014).

\subsection{Application to North Sea Plaice}

The model is applied to a stylized setting for the management of North Sea plaice, for which parameter values have been derived in Dijk et al. (2013). North Sea plaice is a commercially 
exploited flatfish in the EU, with catch mainly coming from demersal towed gears, otter trawls, beam trawls and anchor seines. Since the 1950s, the fishing industry has contributed significantly to the change in growth of the North Sea plaice stock and has affected the stock biomass, spawning stock biomass and harvest (Rijnsdorp and Leeuwen 1996). More specifically, growth increased between 1960 and 1970, stabilized between 1970 and 1977 and decreased abruptly between 1978 and the mid 1980s. In the 1990s, growth stabilized again and since 2010 the stock has been within safe biological limits (Van Keeken et al. 2004; ICES 2013). Particularly low growth rates were observed in 1963, 1972, 1985-1987 and 1996-1997. The success of recent years is related to multiannual management plans, including a quota adjustment restriction, which have been adopted for North Sea plaice by the EU Council in 2007 and put into effect in 2008 (CEC 2007).

For the stylized setting in this paper, biological parameter values are obtained from ICES data (Rijnsdorp and Millner 1996; Grift et al. 2003; Kell and Bromley 2004; Pilling et al. 2008). For economic data the Netherlands are used as representative country for the remaining EU countries that exploit plaice in the North Sea ( Van Balsfoort 2006; Taal et al. 2009; CEC 2007). Fish stock, harvest and quota are measured in kton, while effort and capital stock are measured in terms of millions of horse power days, mln hpd, which is derived from the vessel engine capacity and number of days at sea. In reality, fishing effort is a multidimensional variable, consisting of the number of days at sea, vessel engine capacity, storage capacity, boat length and many other inputs, which to some extent may be mutually substituted. The combination of number of days at sea and vessel engine capacity, hpd, is therefore a useful unit for fishing effort. Note, however, that hpd may be partly replaced by other inputs such as sonar technology and other types of fishing gear. Table 1 gives an overview of parameter and variable values. The model is solved using Matlab.

\subsection{Underlying Assumptions}

In the current version of the model we have assumed that fishermen have a long-term investment-planning horizon and that they each year behave as if the current levels of fish stock and quota will not change over time. Alternative approaches to modeling investment behavior of fishermen may assume different planning horizons, some awareness among fishermen of fish stock dynamics, or rational expectations of fishermen concerning future quota. One way is to include fluctuations in expected quota, so that fishermen expect quota to vary in response to the fish stock and harvest. This adds complexity to the model, because it requires the iterative optimization of both the decisions of fishermen on investment and the policy maker's quota decision in the same stochastic setting. Another way is to assume that fishermen consider a moving average of stock size in their decisions, rather than the current stock size. This approach requires at least one more state variable, i.e. last year's average, which together with the current year's stock determines the new average. An additional state variable increases the dimension of the problem and hence makes the model more complex. Fishermen could also be assumed to consider a probability distribution for the future fish stock and quota. This requires choosing a distribution, a standard deviation and a stochastic process that may not be known. With regard to the policy maker we assume full knowledge on fishermen's decisions, whereas alternative approaches might assume imperfect or even biased information about fishermen's decisions.

This model does not distinguish between the policy maker and fishermen in terms of their risk preference and discount rate. Both decision makers are implicitly considered risk-neutral, but in certain fisheries the decision makers may be risk averse. An alternative approach might specify risk aversion through the direct utility function, such that the decision maker (either 
the policy maker and/or fishermen) is willing to accept lower expected returns in exchange for lower risk. With respect to the assumed discount rate, it may be interesting to assume a divergence between private and social discount rates, such that, possibly, fishermen discount future costs and benefits heavier than policy makers do. Such a divergence has been argued for in the literature. For example, Weitzman (1994) and Weitzman (1998) argue that with increasing income levels and economic activity over time, concerns about environmental externalities become more important. This implies that the social discount rate should be lower than the private discount rate. Also Stern (2007) argues for a low social discount rate, however with the argument that discounting is important only to account for the possibility of extinction of the resource.

Finally, the Spence function assumed in this study is one of many possible harvest functions. In the fisheries economics literature mainly three harvest functions are used, which are the Gordon-Schaefer, Cobb-Douglas and Spence functions. The Gordon-Schaefer function assumes that catch per unit of effort is proportional to the level of fish stock, which remains valid for all levels of effort and fish stock (Gordon 1954; Schaefer 1954). In any 1 year the harvest is a linear function of effort, which makes the catch per unit of effort (CPUE) constant throughout the fishing season for a given fish stock size. It also means that effort can be indefinitely applied in the short run and that harvest increases at a constant rate. These assumptions are not realistic in a discrete time model, because as fishing progresses within the fishing season, CPUE declines due to the declining stock size. The Spence harvest function (Spence 1973) explicitly takes into account this effect of fishing on CPUE within one fishing season. This function resembles the Baranov function (Baranov 1918), which is often used by biologists. Similar to the Gordon-Schaefer function, the Cobb-Douglas function assumes decreasing CPUE with harvest, although for the Cobb-Douglas function this property is not derived from the effect of fishing on CPUE through a declining remaining stock. For the discrete-time model in this study, the characteristics of the Spence function make it the most appropriate harvest function. It furthermore allows us to easily derive the open-access escapement and relates most to what biologists use in their models.

\section{Results}

We first look at the effect of a quota adjustment restriction on long-term quota fluctuation. We then introduce a downward environmental shock in the system and study the effect of the quota adjustment restriction on resource rents, overcapacity and recovery of fish stock. Such a shock is a realistic scenario to consider, given the low growth rates of North Sea plaice that were observed in 1963, 1972, 1985-1987 and 1996-1997.

\subsection{Long-Term Effect of a Quota Adjustment Restriction}

Let us first consider the effect of a quota adjustment restriction on quota fluctuation. Based on a simulation of one run with a sample path of 200 years and given initial stock values $x_{0}=350, k_{0}=14$, Fig. 1 illustrates the relative annual change in quota $\left(Q_{t}-Q_{t-1}\right) / Q_{t-1}$, when the quota is not restricted. The relative annual change in quota ranges from -0.17 to 0.37 and has a standard deviation of $\sigma=0.08$. That is, the volatility in quota change is large and results in overcapacity. When a $5 \%$ quota adjustment restriction is applied to the quota, the relative annual change in quota is illustrated in Fig. 2, with given initial stock values $x_{0}=350, k_{0}=14, Q_{0}=65$. The relative annual change in quota ranges from - 0.04 to 0.05 , with a lower volatility of $\sigma=0.02$. 


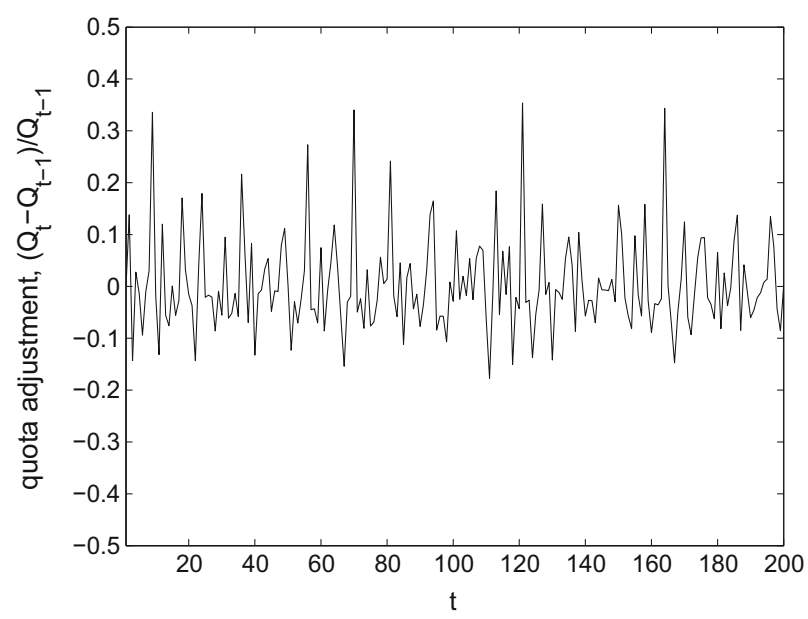

Fig. 1 A 200 years sample path of relative annual quota change $\left(Q_{t}-Q_{t-1}\right) / Q_{t-1}$, with given initial stock values $x_{0}=350, k_{0}=14$; no quota adjustment restriction

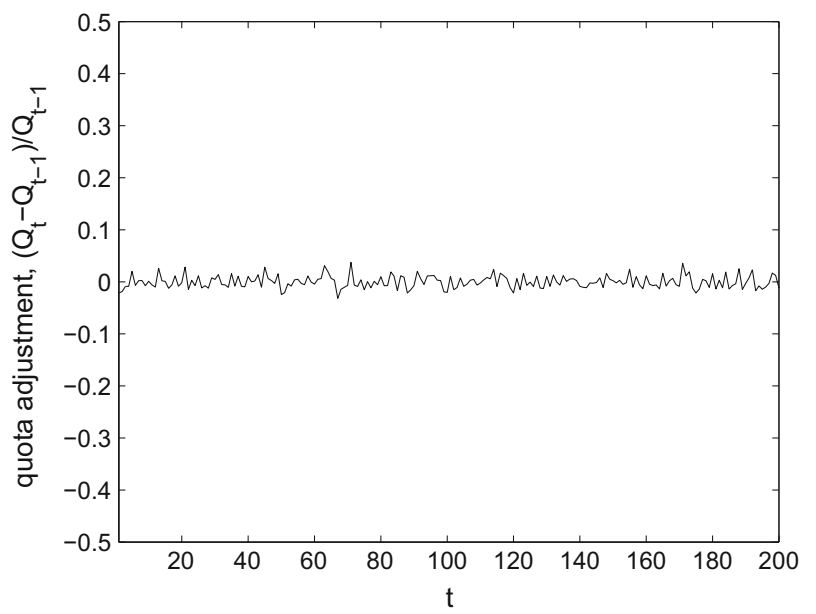

Fig. 2 A 200 years sample path of relative annual quota change $\left(Q_{t}-Q_{t-1}\right) / Q_{t-1}$, with given initial stock values $x_{0}=350, k_{0}=14, Q_{0}=65 ; 5 \%$ quota adjustment restriction

We use the optimal quota $Q_{t}$, derived from Eq. (14), to study the effect of a quota adjustment restriction on long-term average discounted resource rents, overcapacity and fish stock. Table 2 shows results for different levels of quota adjustment restriction, i.e. 30, 15, 10, $5 \%$. Average values of long-term discounted resource rents $\pi_{t}$, overcapacity $k_{t}-E_{t}$, capital stock $k_{t}$, effort $E_{t}$, quota $Q_{t}$, harvest $h_{t}$ and fish stock $x_{t}$ are based on 5,000 sample paths over 100 years each. Furthermore, an estimate is given of the number of years where harvest is bounded by capital stock and quota, i.e. $E_{t}=k_{t}$ and $h_{t}=Q_{t}$ respectively.

Long-term averages of resource rents $\pi_{t}$, quota $Q_{t}$, harvest $h_{t}$ and fish stock $x_{t}$ are little or not affected by a 30 and $15 \%$ quota adjustment restriction. Overcapacity $k_{t}-E_{t}$ is slightly lower under a $30 \%$ adjustment restriction and continues to reduce as the system becomes more restrictive. As has been put forward in Bennear and Stavins (2007), here we observe 


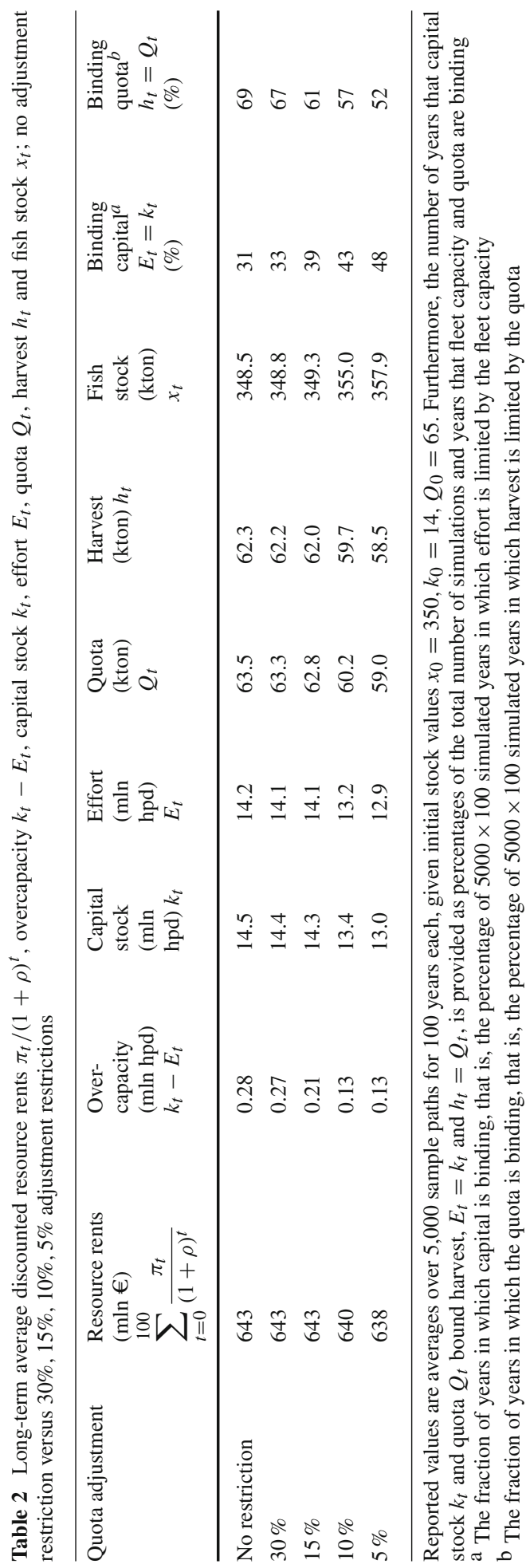


what is to be expected from a restriction, namely sub-optimal decisions lead to a reduction in the net present value of resource rents. Compared to a quota without adjustment restriction, however, under a $5 \%$ quota adjustment restriction resource rents are reduced by $1 \%$ while overcapacity is reduced by $54 \%$. Less overcapacity here, i.e. from 0.28 to 0.13 , is due to keeping a lower capital stock and a lower effort level. This is the reaction of fishermen to a lower long-term quota. Because the policy maker is limited in the adjustment of quota, a lower level is maintained so that uncertain levels of future fish stock, as a consequence of stochastic growth, are anticipated. At the same time, characteristics of the Spence harvest function prevent the fish stock from going extinct (Reed 1979; Nøstbakken 2008). In this model, the Spence harvest function ensures that the fish stock always exceeds the open access fish stock $\hat{x}$. Fishermen therefore do not fully harvest the quota. On one hand, the policy maker tailors the quota to the investment behavior of fishermen, affecting thereby harvest and investment decisions. On the other hand, fishermen assume fixed levels of fish stock and quota over the entire investment planning horizon. Eventually, the effect of the policy and the response of fishermen are observed in the long-term fish stock. With less capital input under a $5 \%$ quota adjustment restriction, harvest decreases as well and the long-term average fish stock increases by $1 \%$.

How often capital stock $E_{t}=k_{t}$ and quota $h_{t}=Q_{t}$ are binding, is shown by the percentages over all 500,000 simulated years. Without quota adjustment restriction, capital is binding $31 \%$ of the simulated years. This percentage increases to $48 \%$ as the system becomes more restrictive. This can be explained by fishermen choosing an effort level that follows the capital stock more closely, where this effort reaches the level of the available capital stock more often. Without an adjustment restriction, the quota is binding $69 \%$ of the time and this reduces to $52 \%$ as we consider a more restrictive quota adjustment. With fishermen reducing overcapacity, it is the capital stock that becomes more often the binding factor, while the quota is less frequently the binding factor.

\subsection{Recovery from an External Shock}

We now turn to the case where the fish stock is temporarily reduced due to an external environmental shock that is not anticipated by the policy maker when setting the quota. This means, the external shock is in addition to the assumption of stochastic growth. The difference is that stochastic growth is anticipated by the policy maker, whereas a shock is an event to which the quota is adjusted at the moment of occurring. With reference to the double objective of the policy maker, i.e. to obtain an efficient fish stock and to reduce overcapacity, we are concerned with the following question. After a downward external shock, what is the effect of a quota adjustment restriction on resource rents, overcapacity and fish stock recovery?

To investigate this question, we simulate the system, where the fish stock reduces instantaneously, but temporarily to $x_{t}=200$ in year $t=20$. Table 3 shows long-term and short-term discounted resource rents $\pi_{t} /(1+\rho)^{t}$, as well as overcapacity $k_{t}-E_{t}$, capital stock $k_{t}$, effort $E_{t}$, quota $Q_{t}$ and harvest $h_{t}$ over a 5 years recovery period, i.e. between $t=20$ and $t=24$. Fish stock recovery $\left|x_{24}-x_{100}\right|$ is measured as the absolute difference between the fish stock in $t=24$ and its long-term average in $t=100$. Again, we consider different levels of quota adjustment restriction, i.e. 30, 15, 10, $5 \%$. Reported values are averages over 5,000 sample paths. Long-term resource rents are taken over a period of 80 years.

The long-run analysis suggests that a restrictive system provides a reduction in overcapacity in exchange for lower resource rents. Table 3 shows that the long-term effect, including recovery from a downward external shock, i.e. the period $t=20$ to $t=100$, provides a 


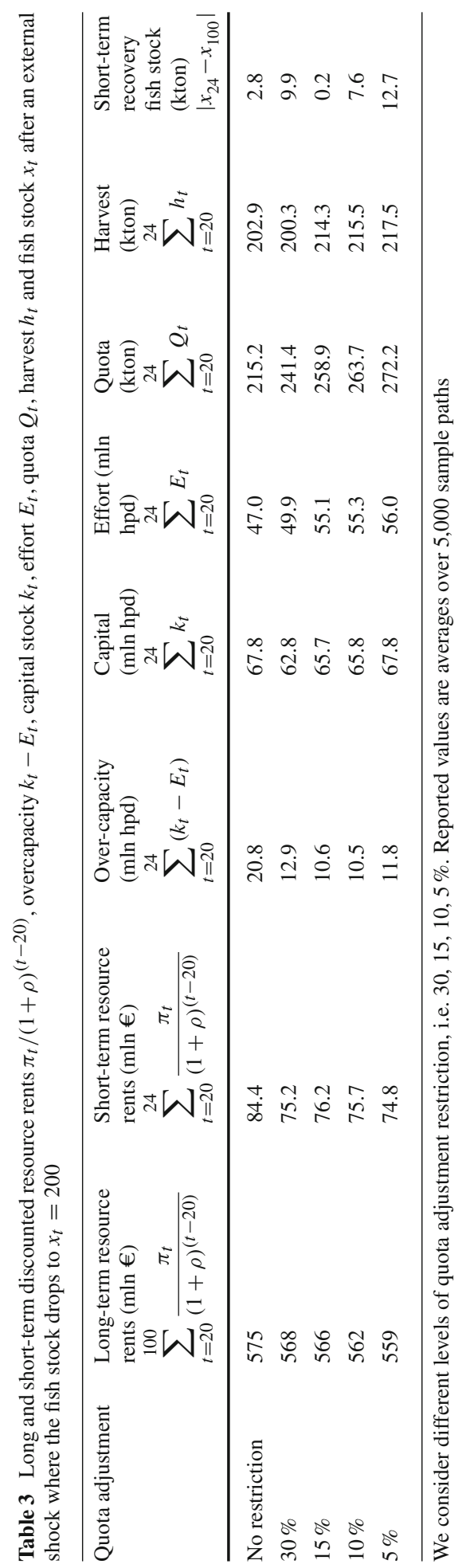


similar conclusion with respect to resource rent reduction. Compared to a quota without adjustment restriction, long-term resource rents can be reduced by $3 \%$ under a $5 \%$ quota adjustment restriction. This is because in the short-term with an adjustment restriction, the policy maker can bring down the quota only by a small amount. During the 5 years recovery period, restricting quota adjustment by more than $30 \%$ has little effect on resource rents. Compared to a quota without restriction, each adjustment restriction provides a $10-11 \%$ decrease in resource rents, regardless of its size. During the same period, overcapacity can be reduced by $38-50 \%$, again independently of the size of the restriction. This is realized by keeping lower levels of capital stock and higher levels of effort as a result of setting the cumulative quota higher as the system becomes more restrictive. Higher effort also explains the increased cumulative harvest during recovery and a fish stock that, in year $t=24$, is further away from the long-term average.

Figure 3 shows the levels of quota during recovery. Without adjustment restriction, the quota reduces to zero in $t=20$, after which it can be adjusted according to fish stock recovery. Introducing and increasing the level of quota adjustment restriction gives that the quota in $t=20$ is set at a higher level because the adjustment restriction sets a lower bound on the quota. With restriction, the harvest is actually limited by the open access fish stock in $t=20$. This means that on average, the quota in this year is not binding and thereby does not affect the effort level, effort costs and resource rents.

Figure 4 shows how often capital stock is binding, i.e. $E_{t}=k_{t}$, during the 1,000 simulations for each of the years $t=20$ up to $t=40$. In $t=20$ the fish stock reduces to a level at which the capital stock cannot be fully used. The capital stock therefore does not limit effort and harvest under any considered quota adjustment restriction. With fishermen assuming that the fish stock remains at this level throughout the investment planning horizon, the investment level drops to zero and in $t=21$ the capital stock reduces with the fleet depreciation. While the capital stock reduces in $t=21$, the fish stock increases rapidly, causing desired harvest and effort levels to hit the fleet capacity. This occurs in most of the simulations, i.e. $89-100 \%$, under 15,10 and $5 \%$ quota adjustment restrictions. If quota adjustment is limited to $30 \%$ or not limited at all, the number of times that the full capacity is reached remains low,

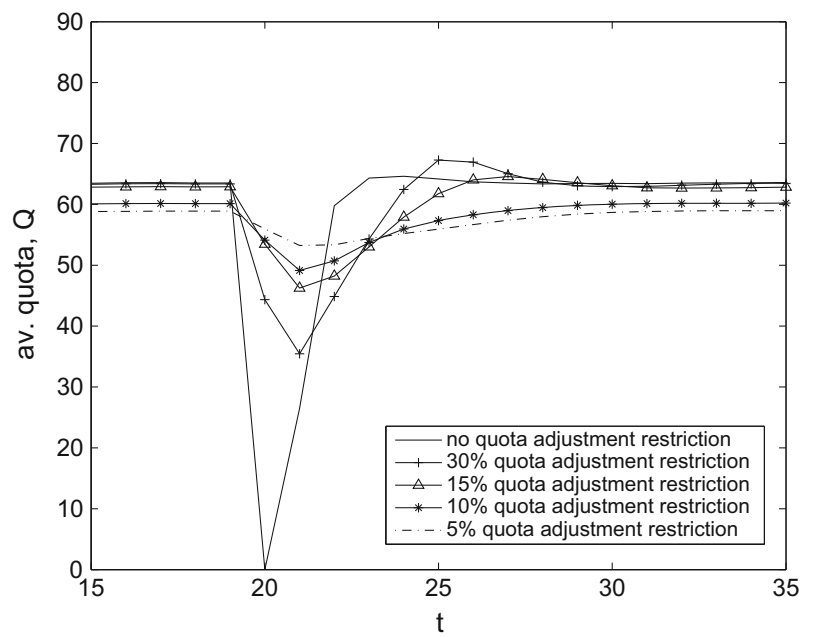

Fig. 3 Average quota $Q_{t}$ over 5,000 sample paths of 20 years each, without and with different levels of quota adjustment restriction, i.e. $30,15,10,5 \%$, and given a downward shock in $t=20$ 


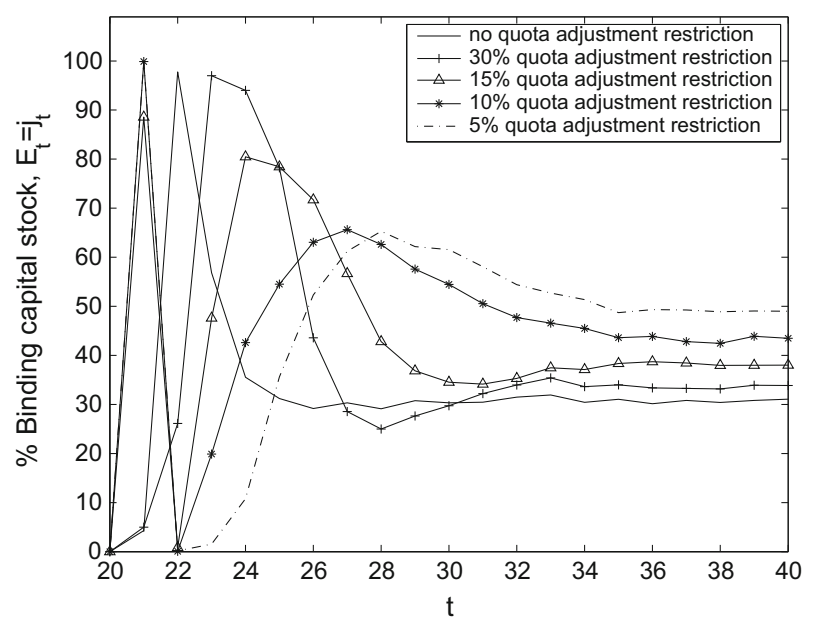

Fig. 4 Binding capital stock $E_{t}=k_{t}$ as a percentage of 5,000 simulations in the 20 years period after the shock

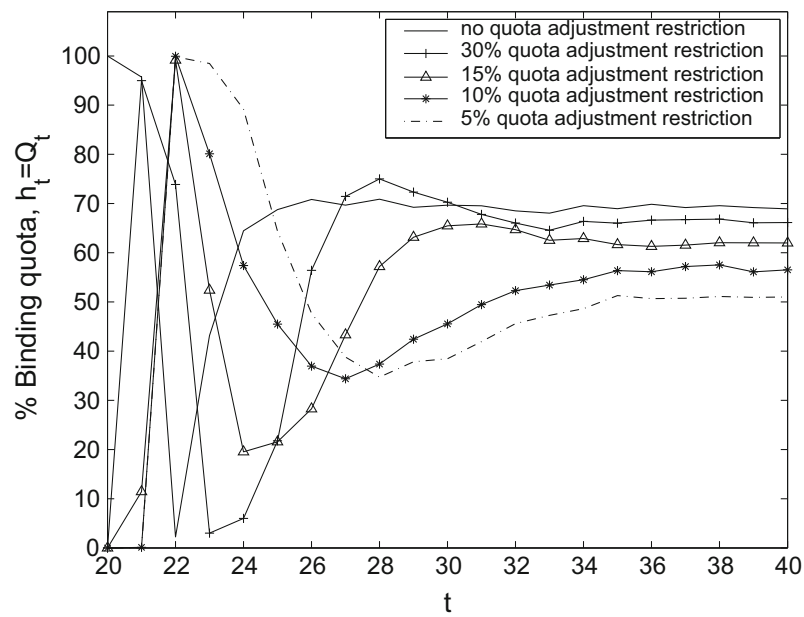

Fig. 5 Binding quota $h_{t}=Q_{t}$ as a percentage of 5,000 simulations in the 20years period after the shock

i.e. $4-5 \%$, as it is the quota that limits the harvest. Due to the large investment under 15,10 and $5 \%$ quota adjustment restrictions, in $t=22$ a large fleet capacity becomes available. A $30 \%$ quota adjustment restriction, or no restriction, causes investment to be small in $t=21$ such that the fleet capacity becomes more restrictive in $t=22$, i.e. $26-98 \%$. In the following years, the difference fades out because the fish stock approaches its long-term average.

Figure 5 shows how often quota is binding $h_{t}=Q_{t}$ during the years $t=20$ up to $t=40$. In the year of the shock, only a restriction-free system can follow the downward movement of the harvest in $100 \%$ of the simulations. With an adjustment restriction, the quota cannot follow and is not binding. Although the fish stock is able to increase rapidly at a zero quota, it is still in recovery in $t=21$, such that harvest is limited by quota in a large number of the simulations, i.e. $96 \%$. The 30 and $15 \%$ quota adjustment restrictions provide the same tendency. The investment in year $t=21$ increases, especially in a system with no adjustment restriction because of the zero quota and zero investment in the previous year. Consequently, 
in $t=22$ the desired open access harvest $\tilde{h}\left(x_{t}\right)=\left(x_{t}-\hat{x}\right)^{+}$exceeds the quota. This provides a large number of simulations, i.e. $99-100 \%$, of harvest being limited by the quota under a 15 10 and $5 \%$ adjustment restriction. In the following years, the system recovers from the shock and returns to its long-term state where a quota with adjustment restriction is less limiting for harvest than a quota without restriction.

\subsection{Sensitivity Analysis}

To analyze to what extent results change due to changes in parameter values, we conduct a sensitivity analysis. Table 4 in "Appendix 1" shows the effect of changes in economic parameters on long-term average values of resource rents, overcapacity, capital stock, effort, quota, harvest and fish stock. In a ceterus paribus analysis, we considered a $50 \%$ increase in the effort $\operatorname{cost} c_{E}$, crew $\operatorname{cost} c_{R}$ and investment $\operatorname{cost} c_{I}$ each; a $25 \%$ price $(p)$ increase; a $100 \%$ increase in the vessel depreciation rate $(\gamma)$; a reduction of the discount factor $(\delta)$ to 0.85 . Results are compared with the baseline results in Table 2.

Compared to the baseline, results confirm the expectation that at an increase in effort, investment and crew costs, resource rents decrease under all levels of quota adjustment restriction (including no restriction). A lower discount factor, implying that future resource rents are valued less, reduces long-term discounted resource rents most. For example, without restriction resource rents reduce from $643 \mathrm{mln} €($ in the baseline) to $216 \mathrm{mln} €$. Only a higher price results in higher resource rents; without restriction, resource rents increase from 643 mln $€($ in the baseline) to $1097 \mathrm{mln} €$.

A higher investment cost comes with an incentive to reduce vessel purchases and to keep idle capital at low levels. Both investment levels and overcapacity are therefore reduced, which is translated into a relatively small reduction in resource rents. Note that, compared to the baseline, overcapacity increases as the quota adjustment becomes more restrictive (from $0.01 \mathrm{mln}$ hpd without adjustment restriction to $0.13 \mathrm{hpd}$ with a $5 \%$ adjustment restriction). This increase is somewhat counter-intuitive, but may be explained along the standard deviation $(\sigma)$ of overcapacity. In the baseline, overcapacity has a standard deviation that ranges between $\sigma=0.02$ (for 15 and $10 \%$ quota adjustment restrictions) and $\sigma=0.03$ (for no restriction as well as 30 and $5 \%$ quota adjustment restrictions). At a higher investment cost, we find that the sigma of overcapacity decreases as the system becomes more restrictive; the standard deviation decreases from $\sigma=0.06$ (no restriction) to $\sigma=0.04$ (5\% restriction). Although long-term overcapacity increases as the system becomes more restrictive, there is less fluctuation, hence the lower $\sigma$. In fact, at a $5 \%$ quota adjustment restriction, overcapacity and its $\sigma$ are at the level of the baseline. Note, however, that at a higher investment cost absolute levels of overcapacity are very low between no restriction and a $10 \%$ adjustment restriction. Due to such low levels the quota is still reduced under a more restrictive quota adjustment system, as well as capital stock, effort and harvest.

A higher vessel depreciation rate has a similar effect on overcapacity. In this case the idle fleet size is kept at low levels because the size of the fleet decreases more rapidly. As the quota adjustment becomes more restrictive, overcapacity increases and its standard deviation decreases as the system becomes more restrictive. The decrease is between $\sigma=0.07$ at no restriction and $\sigma=0.05$ at a $5 \%$ quota adjustment restriction. Also here it should be noted that absolute levels of overcapacity are low.

Table 5 in "Appendix 1" shows the effect of changes in the economic parameters on resource rents, overcapacity, quota, harvest and fish stock when the fish stock reduces temporarily due to an external shock. We compare with results from the baseline for this scenario (Table 3). Similar to the case without a shock, we find that in the long run the downward 
shock has little effect on resource rents. The increase in effort, investment and crew costs result in lower long-term resource rents, with an additional small reduction caused by the downward shock. Also when we look at the 5-year recovery period only, resource rents are reduced at higher effort, investment and crew costs. The largest reduction is found at a higher effort cost, whereas short-term resource rents increase at a higher price.

With respect to short-term overcapacity, under any scenario this seems to decrease between no restriction and a $10 \%$ quota adjustment restriction. At a $5 \%$ quota adjustment restriction, overcapacity increases slightly, but is still far below the level of no restriction. Note that fishermen assume that the quota and fish stock do not change throughout their investment planning horizon, while during the 5-year recovery period both fish stock and quota change by great amounts. At such a stringent quota adjustment $(5 \%)$ it becomes more difficult for fishermen to adjust to the large changes in fish stock and quota during this 5-year recovery period. The increase in overcapacity may be the result of this.

\section{Summary and Conclusions}

The EU has introduced an adjustment restriction on fish quota to obtain an efficient fish stock and to reduce overcapacity in the fishing industry. We studied the effect of a quota adjustment restriction on the net present value of resource rents, overcapacity and fish stock using a bi-level stochastic dynamic programming model. At level one, the policy maker determines the quota that maximizes expected discounted resource rents, keeping in mind a quota adjustment restriction. At level two, fishermen make their myopic harvest and longterm investment decisions, while being restricted by the quota that is derived at level one.

Our results suggest that without a quota adjustment restriction, volatility in annual quota change is large, which makes it difficult for fishermen to make accurate long-term investment decisions. Consequently, in the long run large quota volatility results in overcapacity for the fishing industry. When a quota adjustment restriction is implemented, annual quota volatility reduces, realizing in the long run both an efficient fish stock and reduced overcapacity. By anticipating uncertain future values of fish stock, the policy maker becomes more conservative and sets the quota at a somewhat lower level than without quota adjustment restriction. Fishermen follow this quota by reducing their effort level and by adjusting their capital stock downward, such that they are less often bounded by quota and they are able to realize a large reduction in overcapacity. The policy maker has to consider the trade-off between resource rents and stability of the system, but the price for less volatility in the quota, i.e. lower expected resource rents, appears to be small. Under a high level of quota adjustment restriction a $54 \%$ reduction in overcapacity can be realized at a $1 \%$ loss in resource rents. Fish stock increases thereby with $1 \%$, so that long-run efficiency of the fish stock is not affected.

We also studied the behavior of the system after a downward environmental shock, where the fish stock reduces temporarily to an extremely low level due to an external factor that policy makers are assumed not to have taken into account. During the recovery period after the shock, both the policy maker and fishermen have to adjust their decisions to the new situation. The policy maker keeps in mind that long-term resource rents are maximized, that the long-term fish stock is kept at a sustainable level and that fishermen in any year choose an effort level that is based on their currently available capital stock and on the currently observed fish stock (or open access fish stock). This is all reflected in the adjustment path of the quota.

In the year of the shock, the reduced fish stock prevents fishermen from using their full fleet capacity. Given that fishermen assume that the future fish stock remains at its currently 
observed level, they not only adjust their investment level to zero, also the current fleet size reduces due to depreciation. The effort level is therefore adjusted downwards. As the fish stock grows in the following year, fishermen have an economic incentive again to increase their fleet capacity. However, with a 1-year lag in the availability of the investment and the continuous growth in fish stock, it takes approximately 7 years for the long-term balance between effort and capital stock to return. The quota only becomes limiting after the capital stock is adjusted to higher levels and the fish stock approaches its long-term average. This holds for all considered quota adjustment restrictions. Over a 5 years recovery period, therefore, all considered quota adjustment restrictions lead to a 10-11\% loss in resource rents compared to the maximized resource rents when adjustment is unrestricted. Hence, also during recovery from an external shock the reduction in overcapacity comes at the cost of a reduction in expected discounted resource rents. The analysis shows that long-term resource rents reduce with the introduction and lower percentage of quota adjustment restriction.

Compared to no restriction, a quota adjustment restriction provides a 38-50\% reduction in overcapacity. Although the external shock reduces the fish stock to an extremely low level, the Spence harvest function assumes that the fish stock cannot be fully harvested. In addition, the quota steers harvest and investment such that, after a shock, the fish stock increases and stabilizes at its long-term average. Although we agree with (Kell et al. 2005) that a quota adjustment restriction delays fish stock recovery, the delay appears to be small and the longterm efficiency is not affected under any restriction. In the long-run, the objective of both obtaining an efficient fish stock and reducing overcapacity for fishermen is realized with a quota adjustment restriction.

Keeping in mind the assumptions made in this study, our results suggest that a quota adjustment restriction can be effective and hence recommended as a policy for the management of North Sea plaice. However, although the policy leads to long-term stability of the fish stock, it should be well-monitored in order to keep some leverage to adjust the quota under extreme conditions that affect the fish stock. In addition, there may be other causes to the problem of fluctuating quota, namely the management procedure itself, which is subject to time-lags between data collection, stock assessment and management implementation. In that case, a quota adjustment restriction addresses the outcome but not the cause of the problem.

The European fish stocks that were studied by means of simulations in Kell et al. (2005) and Kell et al. (2006) include Northeast Atlantic plaice and sole, as well as North Sea cod, haddock, whiting and saithe, Southern and Northern hake, and Eastern and Western Baltic cod. Our optimization model can be adapted to study the effect of a quota adjustment restriction on efficiency of these species and overcapacity, provided that each species has its own growth dynamics and base parameter values.

Acknowledgements The work of the second author has been funded by a grant from the Spanish state (TIN2015-66680).

Open Access This article is distributed under the terms of the Creative Commons Attribution 4.0 International License (http://creativecommons.org/licenses/by/4.0/), which permits unrestricted use, distribution, and reproduction in any medium, provided you give appropriate credit to the original author(s) and the source, provide a link to the Creative Commons license, and indicate if changes were made.

\section{Appendix 1}

When fishermen decide on the long-term investment, they consider depreciation of capital stock $\gamma$ and investment $\operatorname{costs} c_{i} i$, leading to the fishermen profit function (6). Profit $\pi$ depends 
on revenues from harvest $p h$, costs from effort, crew and investment $c_{E} E+c_{R} p h+c_{i} i$. In (5)-(7), fishermen are free to adapt the fleet size in one period to a long-term desired level in case its capacity is insufficient to catch the profit maximizing harvest, which depends on the quota $Q$ and fish stock $x$. After adaptation, effort and the capital stock are at the same constant level $E=k$ and investment $i$ is equal to the depreciated capital stock $\gamma k$. Let us first denote fishermen profit:

$$
\pi=\left(1-c_{R}\right) p h-c_{E} E-c_{i} i
$$

The model uses a Spence harvest function so that effort $E=\frac{1}{q} \ln \left(\frac{x}{x-h}\right)$. We have

$$
i=\gamma k=\gamma E=\frac{\gamma}{q} \ln \left(\frac{x}{x-h}\right)
$$

and profit function (15) can be rewritten as

$$
\pi=\left(1-c_{R}\right) p h-\frac{\left(c_{E}+c_{i} \gamma\right)}{q} \ln \left(\frac{x}{x-h}\right) .
$$

The maximum of $\pi$ in (17) with respect to harvest $h$ can be derived from the first-order condition that should also take into account that profit is non-negative. This provides us with a harvest level $h=(x-\bar{x})^{+}$where

$$
\bar{x}=\frac{c_{E}+c_{i} \gamma}{p q\left(1-c_{R}\right) p} .
$$

However, harvest is also constrained by quota $Q$, such that the optimum harvest level is

$$
h=\min \left\{x-\frac{c_{E}+c_{i} \gamma}{p q\left(1-c_{R}\right)}, Q\right\} .
$$

If the current fleet size is not sufficient for the long-run desired effort level $\bar{E}=\frac{1}{q} \ln \left(\frac{x}{x-\bar{h}}\right)$, fishermen can directly, i.e. in 1 year, arrive at the desired capital stock by investing the difference between desired effort $\bar{E}$ and the depreciated capital stock $(1-\gamma) k$. If the capital stock exceeds that level in the next period, no investment needs to be made. This gives the following investment decision

$$
i=\left\{\frac{1}{q} \ln \left(\frac{x}{x-\bar{h}}\right)-(1-\gamma) k\right\}^{+} .
$$

\section{Appendix 2}

See Tables 4 and 5. 
$\dot{3}$

总

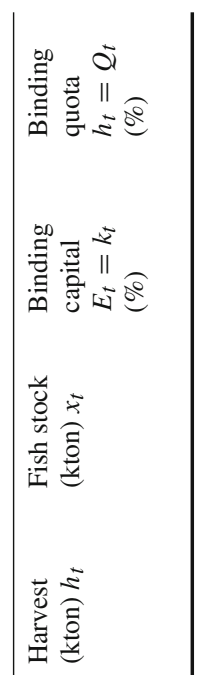

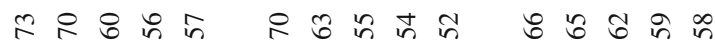

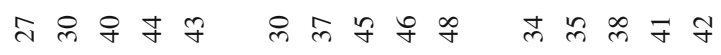

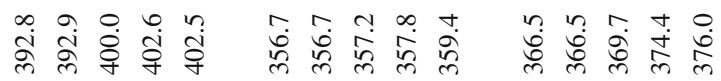

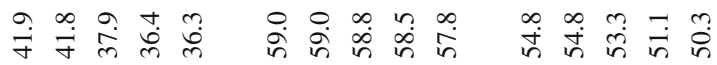

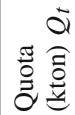

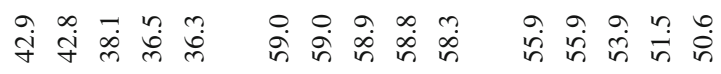

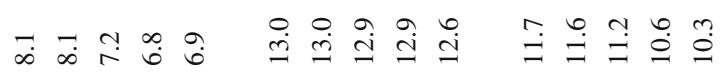

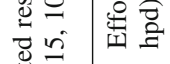

-

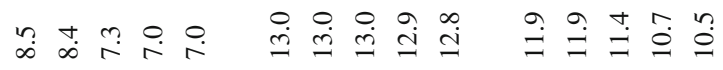

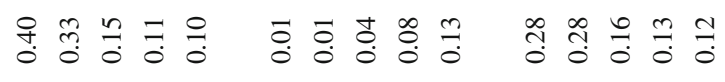

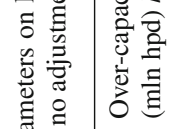

웅으응응

$\begin{array}{ll} & \\ 0 \\ 0\end{array}$

政

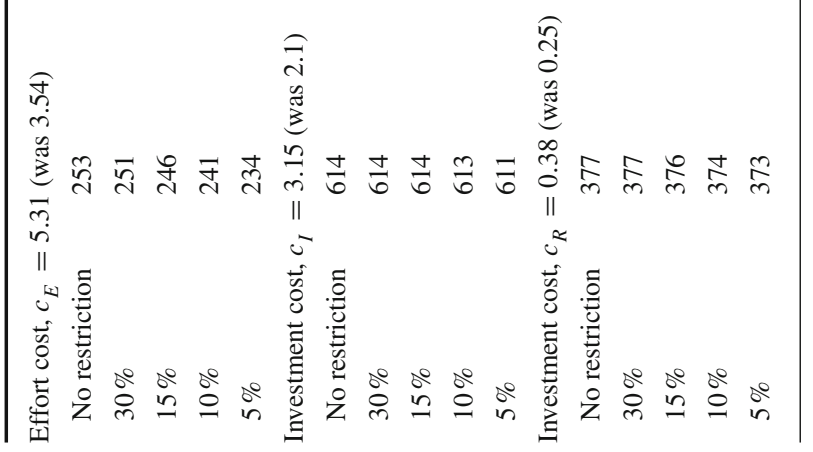




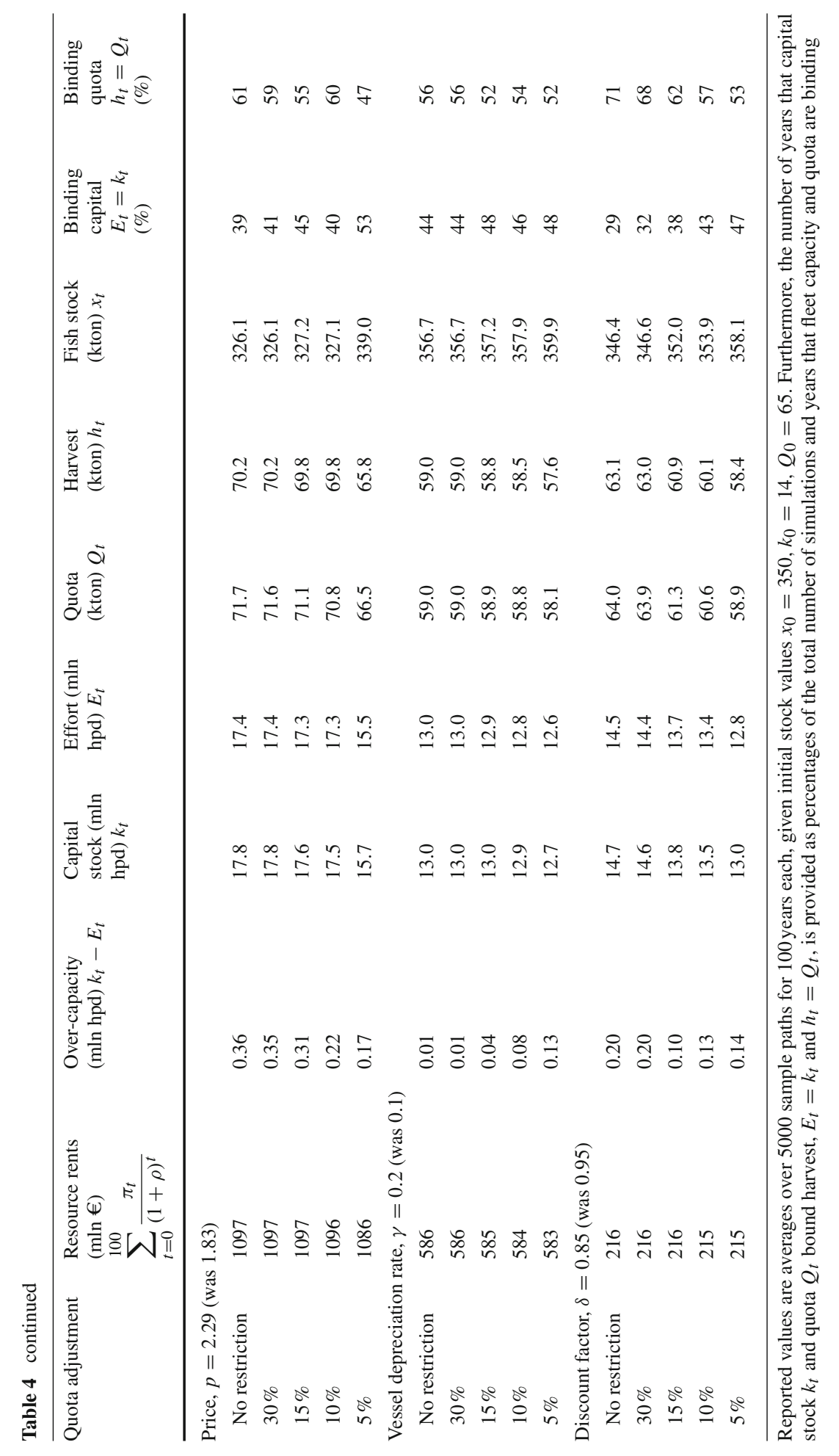




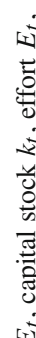

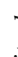

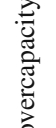

ช

I

$+$

$\pm$

5
0
0
0
0

产

㺃

总

产

要

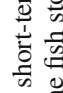

क्ष

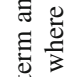

कo

ㅎ

氙

跑

สี

完

过

ठ ठ

ज)

을

㐘

总

近焉

in 0

䒕

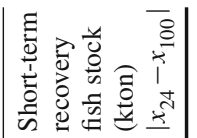

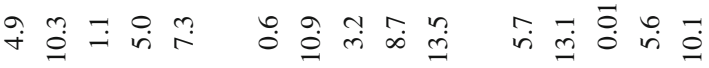

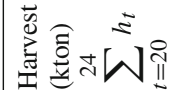

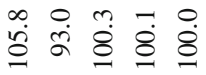

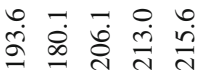

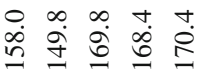

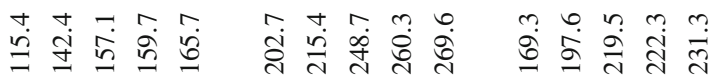

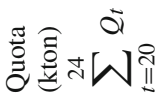

踶

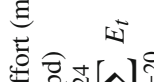

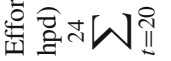

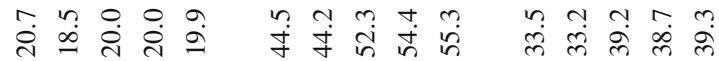

चु है ₹

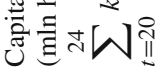

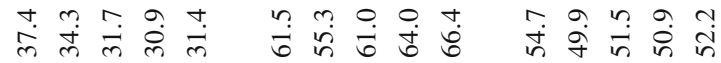

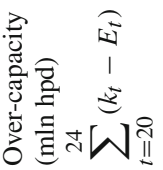

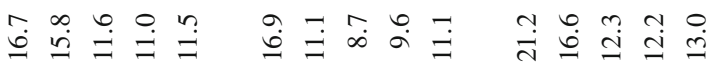

ñ

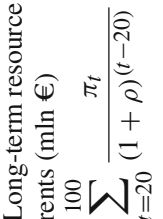

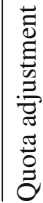

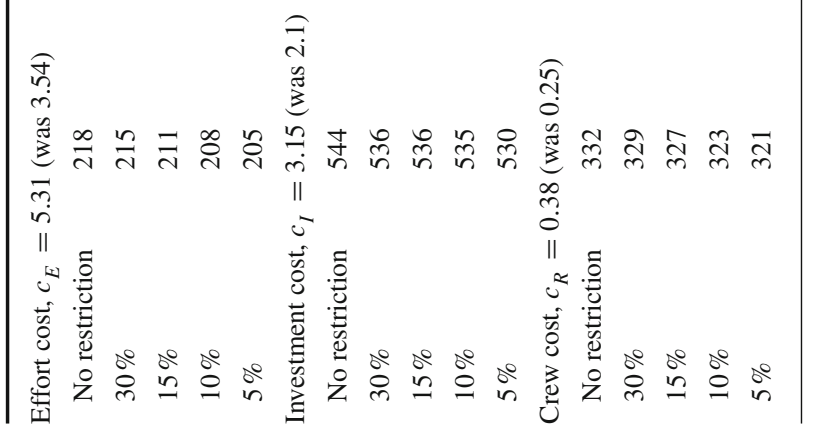




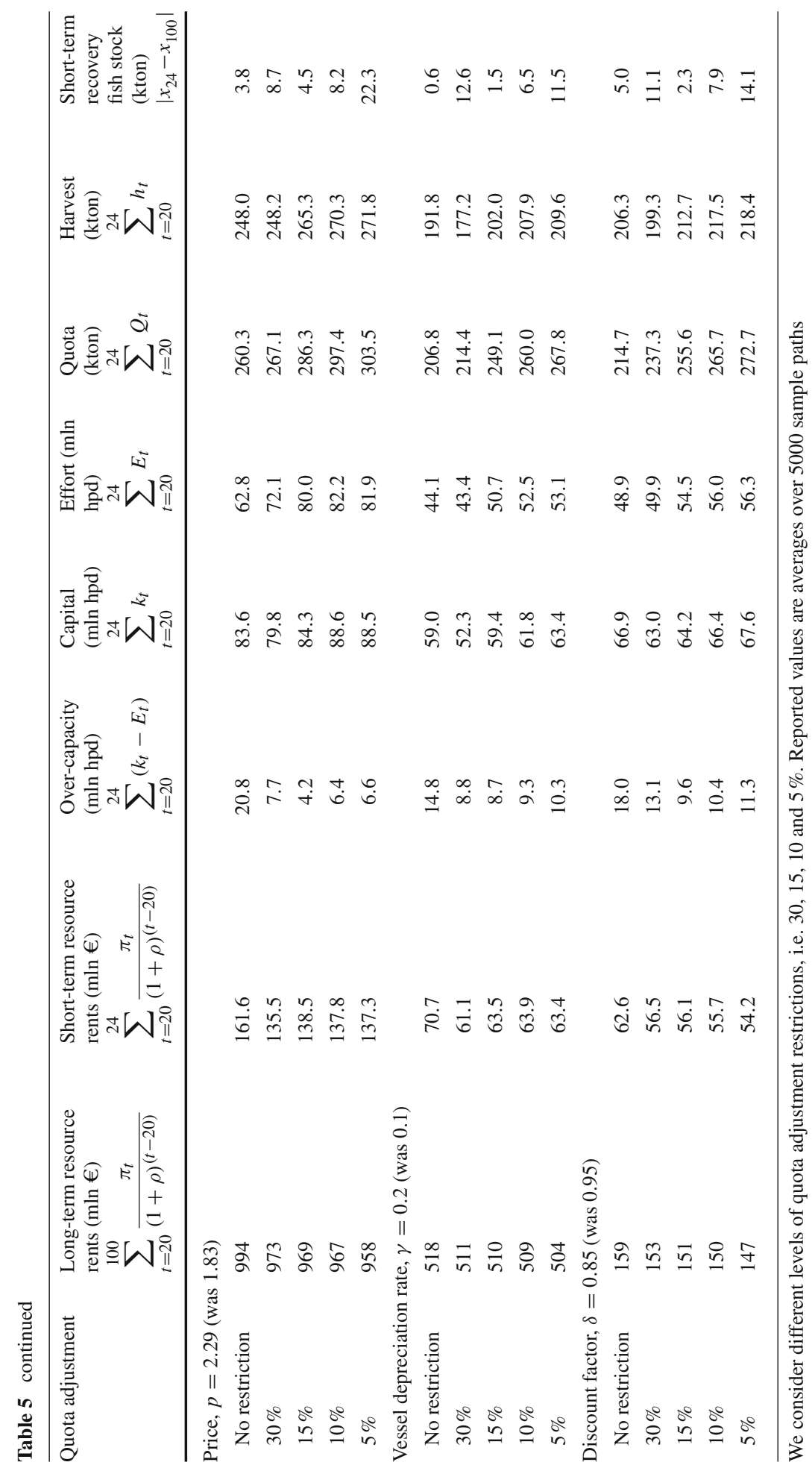




\section{References}

Anderson LG (2000) Open access fisheries utilization with endogenous regulatory structure: an expanded analysis. Ann Oper Res 94:231-257

Arnason R (2009) Fisheries management and operations research. Eur J Oper Res 193(3):741-751

Bailey M, Sumaila UR, Lindroos M (2010) Application of game theory to fisheries over three decades. Fish Res 102(1-2):1-8

Baranov FI (1918) On the question of the biological basis of fisheries. Nauch Issledov Iktiol Inst Izv 1(1):81128

Bennear L, Stavins R (2007) Second-best theory and the use of multiple policy instruments. Environ Res Econ 37:111-129

Butterworth DS (2007) Why a management procedure approach? Some positives and negatives. ICES J Mar Sci J Cons 64(4):613-617

Carson R, Granger C, Jackson J, Schlenker W (2009) Fisheries management under cyclical population dynamics. Environ Res Econ 42:379-410

CEC (2007) Establising a multiannual plan for fisheries exploiting stocks of plaice and sole in the north sea. Technical Report No 676/2007 of 11 June 2007, Council Regulation (EC). http://eur-lex.europa.eu/ LexUriServ/LexUriServ.do?uri=OJ:L:2007:157:0001:0006:EN:PDF

Clark CW (2006) The worldwide crisis in fisheries: economic models and human behavior. Cambridge University Press, Cambridge

Clark CW, Munro GR, Sumaila UR (2005) Subsidies, buybacks, and sustainable fisheries. J Environ Econ Manag 50(1):47-58

Conrad JM, Clark CW (1987) Natural resource economics: notes and problems. Cambridge University Press, Cambridge

Da Rocha J, Gutiérrez M (2012) Endogenous fishery management in a stochastic model: why do fishery agencies use TACs along with fishing periods? Environ Res Econ 53:25-59

Daníelsson A (2005) Methods for environmental and economic accounting for the exploitation of wild fish stocks and their applications to the case of icelandic fisheries. Environ Res Econ 31:405-430

Eisenack K, Welsch H, Kropp J (2006) A qualitative dynamical modelling approach to capital accumulation in unregulated fisheries. J Econ Dyn Control 30(12):2613-2636

Elliston L, Cao L (2006) An agent-based bioeconomic model of a fishery with input controls. Math Comput Model 44:565-575

European Commission (2009) The common fisheries policy—a user's guide. Technical Report chapter 6, European Commission

Europêche (2011) The reform of the CFP: the essential demands of the sector. Technical Report EP(11)39/SP(11)1835/AQ(11)1877. Final, Association des Organisations Nationales d'Entreprises de Pêche de l'UE

Fulton EA, Smith AD, van Putten IE (2011) Human behaviour: the key source of uncertainty in fisheries management. Fish Fish 12:2-17

Gordon H (1954) The economic theory of a common property resource: the fishery. J Polit Econ 62(2):124-142

Grafton RQ, Arnason R, Bjorndal T, Campbell D, Campbell HF, Clark CW, Connor R, Dupont DP, Hannesson R, Hilborn R, Kirkley JE, Kompas T, Lane DE, Munro GR, Pascoe S, Squires D, Steinshamn SI, Turris BR, Weninger Q (2006) Incentive-based approaches to sustainable fisheries. Can J Fish Aquat Sci 63(3):699_ 710

Grafton RQ, Kompas T, Chu L, Che N (2010) Maximum economic yield. Aust J Agric Res Econ 54(3):273-280

Grift RE, Rijnsdorp AD, Barot S, Heino M, Dieckmann U (2003) Fisheries induced trends in reaction norms for maturation in North Sea plaice. Mar Ecol Prog Ser 257:247-257

Guyader O (2002) Simulating the effect of regulatory systems in a fishery, an application to the French driftnet Albacore fleet. Environ Res Econ 23:1-28

Hämäläinen RP, Ruusunen J, Kaitala V (1990) Cartels and dynamic contracts in sharefishing. J Environ Econ Manag 19(2):175-192

Homans FR, Wilen JE (1997) A model of regulated open access resource use. J Environ Econ Manag 32(1):121

Howard RA (1960) Dynamic programming and Markov processes. Technology Press and Wiley, New York ICES (2013) ICES advice June 2013-report of the ICES advisory comittee, book 6.4.18. Technical Report, International Council for the Exploration of the Sea. http://www.ices.dk/sites/pub/Publication

Judd KL (1998) Numerical methods in economics, vol 1, 1st edn. MIT Press Books, Cambridge

Karagiannakos A (1996) Total allowable catch (TAC) and quota management system in the European Union. Mar Policy 20(3):235-248 
Kell L, Bromley P (2004) Implications for current management advice for North Sea plaice (Pleuronectes platessa L.): part ii. increased biological realism in recruitment, growth, density-dependent sexual maturation and the impact of sexual dimorphism and fishery discards. J Sea Res 51(3-4):301-312

Kell L, Pastoors M, Scott R, Smith M, Van Beek F, O’Brien C, Pilling G (2005) Evaluation of multiple management objectives for Northeast Atlantic flatfish stocks: sustainability vs. stability of yield. ICES J Mar Sci J Conseil 62(6):1104-1117

Kell LT, Pilling GM, Kirkwood GP, Pastoors MA, Mesnil B, Korsbrekke K, Abaunza P, Aps R, Biseau A, Kunzlik P, Needle CL, Roel BA, Ulrich C (2006) An evaluation of multi-annual management strategies for ICES roundfish stocks. ICES J Mar Sci J Conseil 63(1):12-24

Kronbak L, Lindroos M (2006) An enforcement-coalition model: fishermen and authorities forming coalitions. Environ Res Econ 35:169-194

Kulmala S, Laukkanen M, Michielsens C (2008) Reconciling economic and biological modeling of migratory fish stocks: optimal management of the Atlantic salmon fishery in the Baltic Sea. Ecol Econ 64(4):716728

Link P, Schneider U, Tol R (2011) Economic impacts of changes in fish population dynamics: the role of the fishermen's harvesting strategies. Environ Model Assess 16:413-429

Munro G, Sumaila UR, Turris B (2012) Catch shares, the theory of cooperative games and the spirit of Elinor Ostrom: a research agenda. In: Conference proceedings from IIFET 2012

Nielsen JR (2003) An analytical framework for studying: compliance and legitimacy in fisheries management. Mar Policy 27:425-432

Nøstbakken L (2008) Stochastic modelling of the North Sea herring fishery under alternative management regimes. Mar Res Econ 23:65-86

Olaussen JO, Skonhoft A (2008) On the economics of biological invasion: an application to recreational fishing. Nat Res Model 21(4):625-653

Pauly D, Christensen V, Guénette S, Pitcher TJ, Sumaila UR, Walters CJ, Watson R, Zeller D (2002) Towards sustainability in world fisheries. Nature 418:689-695

Pilling GM, Kell LT, Hutton T, Bromley PJ, Tidd AN, Bolle LJ (2008) Can economic and biological management objectives be achieved by the use of MSY-based reference points? a North Sea plaice (Pleuronectes platessa) and sole (Solea solea) case study. ICES J Mar Sci J Conseil 65(6):1069-1080

Puterman ML (1994) Markov decision processes: discrete stochastic dynamic programming. Wiley, New York

Quinn J, Ruseski G (2001) Effort subsidies and entry deterrence in transboundary fisheries. Nat Res Model 14(3):369-389

Reed WJ (1979) Optimal escapement levels in stochastic and deterministic harvesting models. J Environ Econ Manag 6(4):350-363

Rijnsdorp AD, Millner RS (1996) Trends in population dynamics and exploitation of North Sea plaice (Pleuronectes platessa L.) since the late 1800s. ICES J Mar Sci J Conseil 53(6):1170-1184

Rijnsdorp AD, van Leeuwen P (1996) Changes in growth of north sea plaice since 1950 in relation to density, eutrophication, beam-trawl effort, and temperature. ICES J Mar Sci J Conseil 53:1199-1213

Ruseski G (1998) International fish wars: the strategic roles for fleet licensing and effort subsidies. J Environ Econ Manag 36(1):70-88

Sandal LK, Steinshamn SI (2004) Dynamic Cournot-competitive harvesting of a common pool resource. J Econ Dyn Control 28(9):1781-1799

Schaefer M (1954) Some aspects of the dynamics of populations important to the management of commercial fisheries. Bull Inter Am Trop Tuna Comm 1:25-56

Singh R, Weninger Q, Doyle M (2006) Fisheries management with stock growth uncertainty and costly capital adjustment. J Environ Econ Manag 52(2):582-599

Spence M (1973) Blue Whales and applied control theory. Technical Report 108, Institute for Mathematical Studies, Stanford University

Stern N (2007) The economics of climate change: the Stern review. Cambridge University Press, Cambridge

Taal C, Bartelings H, Beukers R, Duijn Av, Oostenbrugge Jv (2009) Visserij in cijfers (Fishery in numbers) 2009. Report LEI 2009-070, Den Haag, LEI Wageningen UR

Tsitsika EV, Maravelias CD (2008) Fishing strategy choices of purse seines in the Mediterranean: implications for management. Fish Sci 74(1):19-27

Van Balsfoort G (2006) Vissen met tegenwind: advies task force Duurzame Noordzee visserij. Technical Report, Dutch Fish Product Board, Rijswijk

van Dijk D, Haijema R, Hendrix EMT, Groeneveld RA, van Ierland EC (2013) Fluctuating quota and management costs under multiannual adjustment of fish quota. Ecol Model 265:230-238

van Dijk D, Hendrix EMT, Haijema R, Groeneveld RA, van Ierland EC (2014) On solving a bi-level stochastic dynamic programming model for analyzing fisheries policies: Fishermen behavior and optimal fish quota. Ecol Model 272:68-75 
Van Keeken O, Kraak S, Rijnsdorp AD (2004) Growth and maturity of north sea plaice and sole. Technical Report C088.04, RIVO-Netherlands Institute for Fisheries Research

Weitzman M (1994) On the environmental discount rate. J Environ Econ Manag 26:200-209

Weitzman M (1998) Why the far-distant future should be discounted at its lowest possible rate. J Environ Econ Manag 36:201-208 